\title{
Muscarinic Inhibition of Hypoglossal Motoneurons: Possible Implications for Upper Airway Muscle Hypotonia during REM Sleep
}

\author{
는 Zhu, Nancy L. Chamberlin, and ${ }^{-E}$ Elda Arrigoni \\ Department of Neurology, Beth Israel Deaconess Medical Center and Harvard Medical School, Boston, Massachusetts 02215
}

Proper function of pharyngeal dilator muscles, including the genioglossus muscle of the tongue, is required to maintain upper airway patency. During sleep, the activity of these muscles is suppressed, and as a result individuals with obstructive sleep apnea experience repeated episodes of upper airway closure when they are asleep, in particular during rapid-eye-movement (REM) sleep. Blocking cholinergic transmission in the hypoglossal motor nucleus (MoXII) restores REM sleep genioglossus activity, highlighting the importance of cholinergic transmission in the inhibition of hypoglossal motor neurons (HMNs) during REM sleep. Glutamatergic afferent input from neurons in the parahypoglossal $(\mathrm{PH})$ region to the HMNs is critical for MoXII respiratory motor output. We hypothesized that statedependent cholinergic regulation may be mediated by this pathway. Here we studied the effects of cholinergic transmission in HMNs in adult male and female mice using patch-clamp recordings in brain slices. Using channelrhodopsin-2-assisted circuit mapping, we first demonstrated that $\mathrm{PH}$ glutamatergic neurons directly and robustly activate HMNs ( $\mathrm{PH}^{\text {Glut }} \rightarrow \mathrm{HMNs}$ ). We then show that carbachol consistently depresses this input and that this effect is presynaptic. Additionally, carbachol directly affects HMNs by a variable combination of muscarinic-mediated excitatory and inhibitory responses. Altogether, our results suggest that cholinergic signaling impairs upper airway dilator muscle activity by suppressing glutamatergic input from PH premotoneurons to HMNs and by directly inhibiting HMNs. Our findings highlight the complexity of cholinergic control of HMNs at both the presynaptic and postsynaptic levels and provide a possible mechanism for REM sleep suppression of upper airway muscle activity.

Key words: brain slices; cholinergic transmission; electrophysiology; mice; muscarinic receptors; optogenetics

Significance Statement

Individuals with obstructive sleep apnea can breathe adequately when awake but experience repeated episodes of upper airway closure when asleep, in particular during REM sleep. Similar to skeletal postural muscles, pharyngeal dilator muscles responsible for maintaining an open upper airway become hypotonic during REM sleep. Unlike spinal motoneurons controlling postural muscles that are inhibited by glycinergic transmission during REM sleep, hypoglossal motoneurons that control the upper airway muscles are inhibited in REM sleep by the combination of monoaminergic disfacilitation and cholinergic inhibition. In this study, we demonstrated how cholinergic signaling inhibits hypoglossal motoneurons through presynaptic and postsynaptic muscarinic receptors. Our results provide a potential mechanism for upper airway hypotonia during REM sleep.

\section{Introduction}

Individuals with obstructive sleep apnea (OSA) are predisposed to upper airway collapse during sleep. In these individuals, the progressive loss of pharyngeal dilator muscle tone during sleep

\footnotetext{
Received Feb. 27, 2019; revised July 8, 2019; accepted Aug. 13, 2019.

Author contributions: L.Z., N.L.C., and E.A. designed research; L.Z. performed research; L.Z. analyzed data; L.Z., N.L.C., and E.A. wrote the paper.

This study was supported by National Institutes of Health Grant 2P01-HL-095491. We thank Dr. Veronique G. VanderHorst for teaching how to make injections in the genioglossus muscle. We also thank Dr. Anne Venner for providing the Python script for the heatmaps. In addition, we thank Dr. Kevin P. Grace and Dr. Patrick M. Fuller for critically reading the manuscript and for helpful suggestions.

The authors declare no competing financial interests.
}

results in constriction of the airway leading to hypoventilation or even apnea if the airway fully collapses. As their arterial $\mathrm{CO}_{2}$ levels rise, patients with OSA make progressively greater respiratory efforts until they arouse and the airway reopens; when they resume breathing, they quickly return to sleep (Malhotra and White, 2002). This cycle repeats itself hundreds of times over the night, resulting in chronic daytime sleepiness, impaired cognitive

Correspondence should be addressed to Lin Zhu at linzhubio@gmail.com or Elda Arrigoni at earrigon@bidmc.harvard.edu.

https://doi.org/10.1523/JNEUROSCI.0461-19.2019

Copyright $\odot 2019$ the authors 
function, and other serious health consequences (Gagnon et al., 2014).

Pharyngeal dilator muscles, including the genioglossus muscle of the tongue are responsible for maintaining upper airway patency (Fuller et al., 1999; Malhotra et al., 2000b; Oliven et al., 2001). These muscles are innervated by the hypoglossal motor nucleus (MoXII; Krammer et al., 1979; Aldes, 1995; Mu and Sanders, 2010). Similar to skeletal postural muscles, activity of the pharyngeal dilator muscles begins to decline with sleep onset and continues to fall in rapid eye movement (REM) sleep (Mezzanotte et al., 1996). The reflexive reopening response to upper airway negative pressure is also reduced in REM sleep, further contributing to the potential for upper airway obstruction (Shea et al., 1999; Carberry et al., 2016). Hypoglossal motoneurons (HMNs), which control upper airway muscles, are regulated differently than the spinal motor neurons in REM sleep. Work by several groups has concluded that HMNs are inhibited by a combination of monoaminergic disfacilitation and cholinergic inhibition (Horner et al., 2014; Kubin, 2016; Rukhadze and Fenik, 2018).

Pharyngeal dilator muscles receive tonic, respiratory, and negative pressure reflex drives that activate HMNs to ensure upper airway patency and protection against collapse during inspiration (White, 2005). The genioglossus muscle is phasically activated during inspiration, whereas tonic activation is maintained during and between breaths (Horner, 2009). Both tonic and respiratory genioglossus activities are state-dependently regulated (Horner et al., 2014). Tonic genioglossus activity is greatly reduced in the transition from wakefulness to non-REM (NREM) sleep, and this is mediated by the withdrawal of noradrenergic and glutamatergic inputs (Horner et al., 1994b; Horner, 2009). Respiratory genioglossus activation is driven by the input from central respiratory generator neurons and the negative pressure reflex (Horner et al., 2014). These two respiratory drives converge onto glutamatergic premotoneurons in the parahyoglossal $(\mathrm{PH})$ region, an area of the reticular formation lateral to the MoXII (Chamberlin et al., 2007; Vann et al., 2018). Electrical stimulation of this region evokes EPSCs in HMNs (Bellingham and Berger, 1996); however, due to the nature of the stimulation it has not been possible to determine whether these synaptic responses were evoked by the stimulation of local neurons or of passing fibers.

Genioglossus respiratory activation is particularly affected during REM sleep (Horner, 2009). Genioglossus activity is depressed by cholinergic agonists, and in REM sleep it is reactivated by the application of muscarinic antagonists in the MoXII (Liu et al., 2005; Grace et al., 2013). How cholinergic signaling inhibits HMNs (i.e., by direct inhibition of the HMNs, by presynaptic suppression of an excitatory input, or both) remains unresolved. Apparently contradictory findings from whole-animal physiology studies in adult animals suggest a muscarinic inhibitory mechanism for genioglossus hypotonia during REM sleep (Horner, 2009; Grace et al., 2013), whereas in vitro electrophysiological studies in neonatal animals emphasize nicotinicmediated activation of HMNs (Zaninetti et al., 1999; Chamberlin et al., 2002). It is hypothesized that developmental changes in cholinergic receptor expression in MoXII neurons might explain these apparent conflicting results (Machaalani et al., 2010; Vivekanandarajah et al., 2015).

In this study, we examined the effects of cholinergic signaling on HMNs and on the afferent input from PH glutamatergic neurons ( $\mathrm{PH}^{\text {Glut }} \rightarrow \mathrm{HMNs}$ ) in brain slices of adult mice. We expressed channelrhodopsin-2 (ChR2) in $\mathrm{PH}$ glutamatergic neurons to isolate the $\mathrm{PH}^{\text {Glut }} \rightarrow \mathrm{HMN}$ input and examined the effect of carbachol on the optogenetic activated $\mathrm{PH}^{\text {Glut }} \rightarrow \mathrm{HMN}$ input.

\section{Materials and Methods}

\section{Experimental design and statistical analysis}

Animals and experimental design. All mice were treated in accordance with guidelines from the National Institutes of Health Guide for the Care and Use of Laboratory Animals, and all protocols were approved by the Beth Israel Deaconess Medical Center Institutional Animal Care and Use Committee. We used 42 VGlut2-ires-Cre mice (23 males and 19 females), 2 ChAT BAC $_{-}$GFP::VGlut2-IRES-Cre mice (2 males), and 21 wild-type $\mathrm{C} 57 \mathrm{BL} / 6 \mathrm{~J}$ mice (11 males and 10 females). All recordings were made from mice that were between 6 and 9 weeks of age.

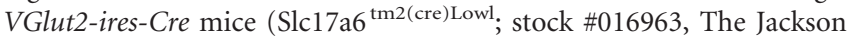
Laboratory) express Cre-recombinase under the control of the vesicular glutamate Transporter 2 (VGlut2) gene allowing restrict recombination in the glutamatergic neurons (Vong et al., 2011). The ChAT $T^{B A C}-e G F P:$ : VGlut2-IRES-Cre mice express Cre-recombinase in VGlut2-expressing neurons and GFP in cholinergic neurons and were obtained by crossing VGlut2-IRES-Cre mice with ChAT $T^{B A C}$-eGFP mice (stock \#007902, The Jackson Laboratory; Tallini et al., 2006). We housed all mice in a pathogen-free animal research facility maintained on a 12 light/dark cycle (lights on at 7:00 A.M.) at $22^{\circ} \mathrm{C}$ ambient temperature and with ad libitum access to food and water.

To test synaptic connectivity between glutamatergic neurons in the $\mathrm{PH}$ region and HMNs $\left(\mathrm{PH}^{\text {Glut }} \rightarrow \mathrm{HMNs}\right.$ ), we expressed ChR2 in the glutamatergic neurons in the $\mathrm{PH}$ region. We placed unilateral microinjections of an adeno-associated virus (AAV) vector coding for cre-dependent ChR2 (AAV-DIO-ChR2-mCherry) into the PH region of VGlut2-IRESCre mice. This AAV-DIO-ChR2-mCherry virus [construct: EF1a-DIOhChR2(H134R)-mCherry prepared into an AAV serotype $8,6 \times 10^{12}$ genomic copies/ml) was prepared by the UNC Gene Therapy Center (University of North Carolina, Chapel Hill; Williams et al., 2014). As previously described (Mochizuki et al., 2011), we injected 37 VGlut2IRES-Cre mice and 2 ChAT $T^{B A C}$-eGFP::VGlut2-IRES-Cre mice with 16.5 $\mathrm{nl}$ of $A A V$-DIO-ChR2- $m$ Cherry in the $\mathrm{PH}$ region [anteroposterior (AP), $+0.2 \mathrm{~mm}$ from the calamus scriptorius; mediolateral (ML), $1.2 \mathrm{~mm}$ from midline; dorsoventral (DV) $-1.3 \mathrm{~mm}$ from the surface of the brain]. For the experiments in which we restricted ChR2 expression to the $\mathrm{PH}$ region at the level of the area postrema, we injected 8 VGlut2-IRES-Cre mice with $3.3 \mathrm{nl}$ of $A A V$-DIO-ChR2-mCherry (AP, + 0.2 from calamus scriptorius; ML, $0.8 \mathrm{~mm}$; DV, $-1.2 \mathrm{~mm}$ ). Three weeks after AAV injections, we prepared coronal brainstem slices containing the MoXII for electrophysiological recordings.

To test synaptic connectivity between $\mathrm{PH}$ glutamatergic neurons and genioglossus motoneurons (GMNs; $\mathrm{PH}^{\text {Glut }} \rightarrow \mathrm{GMNs}$ ), we expressed $\mathrm{ChR} 2$ in $\mathrm{PH}$ glutamatergic neurons and retrogradely labeled GMNs by injecting fluorescent-conjugated Cholera Toxin Subunit B (F-CTB) into the genioglossus muscle of the tongue. We injected 7 VGlut2-IRES-Cre mice with $3.3 \mathrm{nl}$ of $A A V$-DIO-ChR2- $m$ Cherry in the $\mathrm{PH}$ region $(\mathrm{AP},+0.2$ from calamus scriptorius; ML, $0.8 \mathrm{~mm}$; DV, $-1.2 \mathrm{~mm}$ ), and 2 weeks after the AAV injections we injected the genioglossus muscle of the same mice with F-CTB (Invitrogen Alexa Fluor-488-conjugated CTB, Thermo Fisher Scientific. For the tongue injections, we deeply anesthetized the mice initially in an induction chamber (isoflurane, 5\% in oxygen) and then throughout the surgical procedure through a nose mask (isoflurane, $1-2 \%$ in oxygen). We placed the mice supine on a $30^{\circ}$ inclined platform (Kent Scientific) supported with Velcro strips around the hips, abdomen, and chest. With the mouse positioned with head tilted back and the mouth kept open with retractors, we intraorally pressured-injected F-CTB $(594 \mu \mathrm{l})$ through the base of the tongue (at the level of the mandible attachment of the tongue) into the genioglossus muscle (4 $\mathrm{mm}$ in depth). Injections were performed using a glass pipette ( $25 \mu \mathrm{m}$ tip diameter). One week after the tongue injections, we prepared brainstem slices containing the MoXIIs and recorded from fluorescently labeled GMNs.

Slice preparation, whole-cell patch-clamp recordings and ChR2-assisted circuit mapping. To prepare brain slices, we anesthetized mice with iso- 
flurane and then transcardially perfused them with ice-cold artificial CSF [ACSF; $N$-methyl-D-glucamine (NMDG)-based solution], followed by decapitation. We quickly removed the mouse brains and made coronal brainstem slices (250 $\mu \mathrm{m}$ thickness) in ice-cold NMDG-based ACSF using a vibrating microtome (VT1200S, Leica). We incubated the slices containing the MoXII for 6 min at $34^{\circ} \mathrm{C}$ in NMDG-based ACSF, and we then transferred them into a holding chamber containing Na-based ACSF for an additional $10 \mathrm{~min}$ at $34^{\circ} \mathrm{C}$. After this incubation period, we removed the holding chamber from the warm water bath and let the brain slices gradually return to room temperature for at least $30 \mathrm{~min}$. We recorded HMNs expressing GFP and GMNs retrogradely labeled with F-CTB using a combination of fluorescence and infrared (IR)differential interference contrast microscopy. We recorded brain slices submerged and perfused $(2 \mathrm{ml} / \mathrm{min})$ with Na-based ACSF. We used a fixed-stage upright microscope (BX51WI, Olympus America) equipped with a Nomarski water-immersion lens (Olympus $40 \times / 0.8$ numerical aperture) and IR-sensitive CMOS (complementary metal-oxidesemiconductor) camera (Thorlabs). Real-time images were acquired using MATLAB (MathWorks) script software. We recorded neurons at room temperature in whole-cell configuration using a Multiclamp 700B amplifier (Molecular Devices), a Digidata 1322A interface, and Clampex 10 software (Molecular Devices). We monitored the series resistance at regular intervals, and we discarded the data if neurons showed an unstable resting membrane potential or if the series resistance changed by $>25 \%$. We photostimulated the glutamateric $\mathrm{PH}$ input expressing ChR2 using full-field $10 \mathrm{~ms}$ light pulses ( $\sim 10 \mathrm{~mW} / \mathrm{mm}^{2}, 1 \mathrm{~mm}$ beam width; we photostimulated at $0.1 \mathrm{~Hz}$, for a minimum of 30 trials) from a $5 \mathrm{~W}$ Luxeon blue light-emitting diode (470 nm wavelength; \#M470L2-C4, Thorlabs) coupled to the epifluorescence pathway of the microscope. We photostimulated a circular field (500 $\mu$ m radius) around the recorded neurons. Photo-evoked EPSCs were recorded at membrane holding voltage $\left(V_{\mathrm{h}}\right)=-60 \mathrm{mV}$ using a $\mathrm{K}$ gluconate-based pipette solution, and to test monosynaptic connectivity, we recorded photo-evoked EPSCs in the presence of tetrodotoxin (TTX, $2 \mu \mathrm{M}+4$-AP, 1 mM; Hull et al., 2009; Petreanu et al., 2009). We tested the effect of carbachol on HMNs holding currents in voltage-clamp mode $\left(V_{\mathrm{h}}=-60 \mathrm{mV}\right.$; in TTX, $\left.1 \mu \mathrm{M}\right)$.

Histology. Immediately following the in vitro recordings, recorded slices and additional slices containing the injection site were fixed overnight in $10 \%$ buffered formalin and then examined for the ChR2mCherry native fluorescence. We plotted the outline regions containing ChR2-mCherry-expressing neurons onto template drawings (Paxinos and Franklin, 2001) using Photoshop (Adobe). We compiled the distribution of ChR2-mCherry expression in a color map with a Python script (www.python.org; Venner et al., 2016; Ferrari et al., 2018). We represented the region of overlap of the maximum number of overlapping cases in white, with the hues of yellow, orange, to deep red, indicating fewer cases.

For the animals injected with F-CTB in the tongue, immediately following the MoXII slice preparation, we dissected the tongue and fixed it overnight in $10 \%$ buffered formalin. We sectioned the fixed tongues in sagittal slices (50 $\mu \mathrm{m}$ thickness) using a Leica CM1900 Cryostat. We verified the placement of F-CTB in the genioglossus muscle for each of the mice from which we recorded retrogradely labeled GMNs.

Data analysis and statistics. We analyzed all our recording data using Clampfit 10.2 (Molecular Devices), Mini Analysis 6 (Synaptosoft), and MATLAB. Voltage signals were filtered (Gaussian low-pass $400 \mathrm{~Hz}$ cutoff; Clampfit software). To ensure unbiased detection of the synaptic events, the EPSCs were detected and analyzed automatically using Mini Analysis software. We calculated EPSC probability before, during, and after photostimulation. The latency of the photo-evoked EPSCs was taken as the time difference between the start of the light pulse and the onset of the photo-evoked EPSCs as measured by a MATLAB script that calculates the time between the onset of the light pulse and the time when traces cross the threshold sets as the mean minus half the SD of the baseline (baseline value calculated over $3.5 \mathrm{~s}$ just before each light pulse). Photo-evoked EPSC charge amplitudes were calculated as the area under the curve of the photo-evoked EPSCs (in $\mathrm{pA} * \mathrm{~s}$ or $\mathrm{pC}$ ). We concluded that neurons responded to carbachol if holding currents changed by at least $3 \mathrm{pA}$.
Statistical analyses were performed using Prism 7 (GraphPad Software). We normalized all our values by dividing the values of control and treatment samples by the mean of the control samples. Such normalization conserves the distribution and the relative variance of the samples, allowing the subsequent statistical analysis. We represented data as mean \pm SEM, and unless otherwise specified, $n$ refers to the number of neurons per group. We compared means between two normally distributed groups using $t$ tests (paired $t$ test for conditions on the same group of neurons; unpaired $t$ test for two conditions on different groups of neurons). We compared means among multiple normally distributed groups using repeated-measures (RM) one-way ANOVA followed by Tukey's multiple-comparison post hoc test. An $\alpha<0.05$ was considered significant.

\section{Reagents and solutions}

Composition of the NMDG-based ACSF used for slice preparation was as follows (in mM): $100 \mathrm{NMDG}-\mathrm{Cl}, 2.5 \mathrm{KCl}, 20 \mathrm{HEPES}, 1.24 \mathrm{NaH}_{2} \mathrm{PO}_{4}, 30$ $\mathrm{NaHCO}_{3}, 25$ glucose, 2 thiourea, 5 Na-Ascorbate, 3 Na-pyruvate, 0.5 $\mathrm{CaCl}_{2}$, and $10 \mathrm{MgSO}_{4}, \mathrm{pH} 7.3$ with $\mathrm{HCl}$ when carbogenated with $95 \% \mathrm{O}_{2}$ and $5 \% \mathrm{CO}_{2}$. Composition of Na-based ACSF used for recordings was as follows (in mM): $120 \mathrm{NaCl}, 1.3 \mathrm{MgCl}_{2}, 2.5 \mathrm{KCl}, 1.3 \mathrm{MgSO}_{4}, 10$ glucose, 26 $\mathrm{NaHCO}_{3}, 1.24 \mathrm{NaH}_{2} \mathrm{PO}_{4}, 2$ thiourea, $1 \mathrm{Na}$-ascorbate, 3 Na-pyruvate, and $4 \mathrm{CaCl}_{2}, \mathrm{pH} 7.4$ when carbogenated with $95 \% \mathrm{O}_{2}$ and $5 \% \mathrm{CO}_{2}$, 310-320 mOsm. Composition of the pipette solution that we used for both current-clamp and voltage-clamp recordings was as follows (in mM): $120 \mathrm{~K}$-Gluconate, $10 \mathrm{KCl}, 3 \mathrm{MgCl}_{2}, 10 \mathrm{HEPES}, 2.5 \mathrm{~K}$-ATP, and 0.5 $\mathrm{Na}-\mathrm{GTP}, \mathrm{pH} 7.2$ adjusted with $\mathrm{KOH} ; 280 \mathrm{mOsm}$. For the recordings in voltage clamp, we added QX314 (5 mM) to the pipette solution to block action potential firing of the recorded neurons. In a subset of recordings, we added GDP- $\beta$-S ( $1 \mathrm{~mm}$ ) to the pipette solution to block G-proteinmediated signaling (Takahashi et al., 1998; Jin et al., 2013). We purchased TTX from Cayman Chemical. We purchased all other reagents from Sigma-Aldrich. We dissolved drugs in water and then added them to the Na-based ACSF (1:1000 dilution).

\section{Results}

\section{Parahypoglossal glutamatergic neurons directly activate hypoglossal motoneurons}

To study in vitro the afferent input from glutamatergic neurons in the $\mathrm{PH}$ region to the $\mathrm{HMNs}\left(\mathrm{PH}^{\text {Glut }} \rightarrow \mathrm{HMNs}\right)$, we used ChR2assisted circuit mapping in brain slices. The $\mathrm{PH}$ region we refer to here is the same area of the medullary reticular formation that mediates the negative pressure reflex reported by Chamberlin et al., 2007. This area is at the same rostral-caudal level of the MoXII extending $\sim 1 \mathrm{~mm}$ caudal to the obex. The $\mathrm{PH}$ region is directly lateral to the MoXII, and it extends laterally into the intermediate reticular formation (IRt) and part of the parvicellular reticular nucleus up to the lateral edge of the nucleus of the solitary tract.

We injected a cre-dependent $A A V$-DIO-ChR2-mCherry into the PH region of VGlut2-IRES-Cre mice (Krashes et al., 2014), which resulted in the expression of ChR2 in $\mathrm{PH}$ glutamatergic neurons that express VGlut2. Three weeks after the AAV injections, we prepared brain slices for whole-cell recordings. We recorded from HMNs while photostimulating the input from $\mathrm{PH}$ glutamatergic neurons that expressed ChR2 (Fig. 1A).

Histological assessment confirmed the expression of ChR2 in the $\mathrm{PH}$ region in 16 mice in which we recorded photostimulated EPSCs in HMNs. Transduced neurons from individual injections spanned the level of the rostral pole of the MoXII at the level of the area postrema to the level of the pyramidal decussation just posterior to the nucleus ambiguus, with the shared region of transduction for all the mice $(n=16)$ at the area adjacent to the MoXII 0-900 $\mu \mathrm{m}$ caudal to the obex (Fig. $1 B$ ).

Photostimulation of the glutamatergic neurons in the $\mathrm{PH}$ region evoked action potential firing in HMNs and evoked 

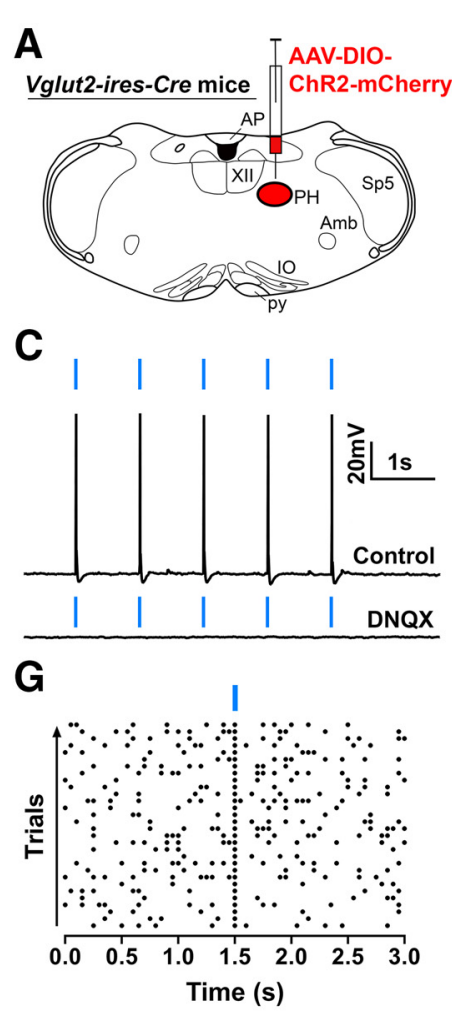
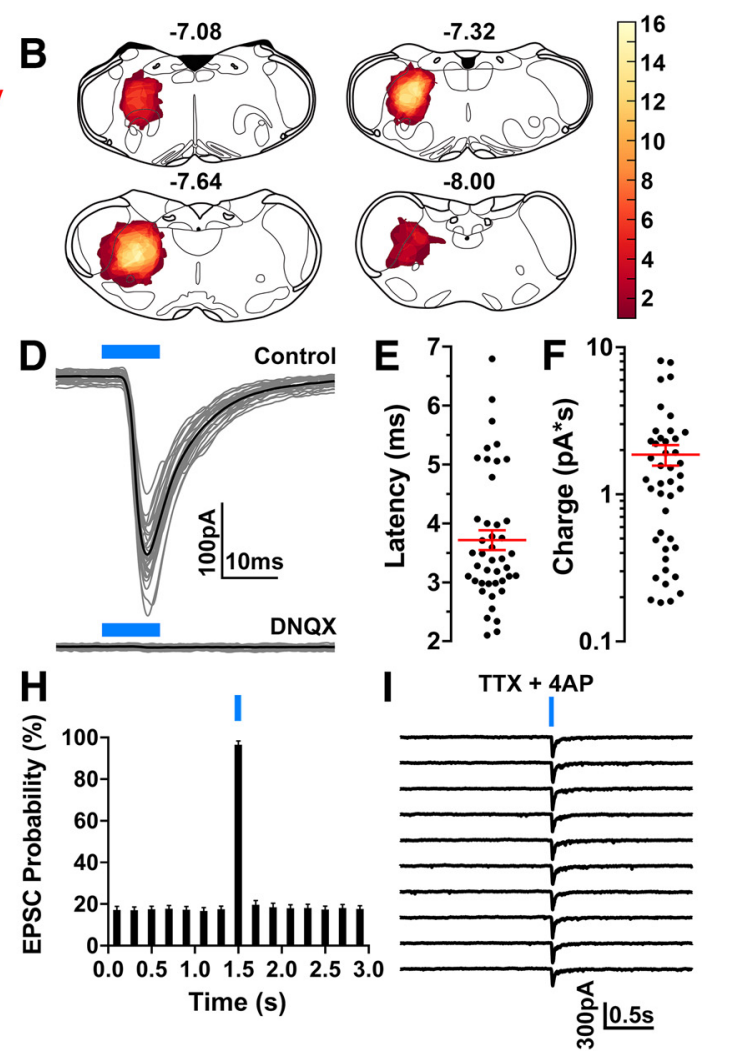

Figure 1. Photostimulation of parahypoglossal glutamatergic neurons activates hypoglossal motoneurons (PH ${ }^{\text {Glut }} \rightarrow$ HMNs). $A$, A schematic diagram of the experimental design we used to study synaptic connectivity between PH glutamatergic neurons and HMNs (PH Glut $\rightarrow$ HMNs). We injected an AAV-DI0-ChR2-mCherry into the PH region of VGlut2-IRES-Cre mice to express ChR2$\mathrm{mCherry}$ in glutamatergic neurons. Three weeks after the AAV injections, we recorded in brain slices and photostimulated $\mathrm{PH}^{\mathrm{Glut}}$ input while recording from HMNs. $\boldsymbol{B}$, Heatmaps of AAV-DIO-ChR2-mCherry injection sites of 16 recorded VGlut2-IRES-Cre mice. The yellow color indicates a higher number of overlapping regions of ChR2-mCherry-expressing neurons. C, Photostimulation of ChR2-expressing $\mathrm{PH}^{\text {Glut }}$ neurons and terminals evoked action potential firing of HMNs (top trace), and this effect was blocked by the AMPA receptor blocker DNQX (20 $\mu \mathrm{m}$; bottom trace), demonstrating the release of glutamate. $\boldsymbol{D}$, In voltage-clamp mode, photostimulation of the $\mathrm{PH}^{\text {Glut }} \rightarrow \mathrm{HMN}$ input evoked short-latency glutamatergic AMPA-mediated EPSCs in HMNs (in gray, 30 photo-evoked EPSC; in black, average photo-evoked EPSC). $\boldsymbol{E}, \boldsymbol{F}$, Photo-evoked EPSC latencies $(\boldsymbol{E})$ and charges $(\boldsymbol{F})$ of photoevoked EPSCS. Black dots, mean values of individual HMNs (average of 30 photostimulation trials); red lines, mean \pm SEM, $n=43$; average photo-evoked EPSC latency: $3.77 \pm 0.17 \mathrm{~ms}$, average photo-evoked EPSC charge: $1.86 \pm 0.30 \mathrm{pA}$ * $\mathbf{S}$ (or pC). $\boldsymbol{G}, \boldsymbol{H}, \mathrm{A}$ representative raster plot (G; 50 ms bins) and average EPSC probability $(\boldsymbol{H})$ upon photostimulation of the PH ${ }^{\text {Glut }}$ input (98.33 \pm $1.44 \% ; n=43)$ and that of baseline without photostimulation $(17.24 \pm 1.62 \% ; n=43) . I$, Photo-evoked EPSCs were maintained in the presence of TTX $(2 \mu \mathrm{m})+4 \operatorname{AP}(1 \mathrm{~mm})$, indicating monosynaptic connectivity. Voltage-clamp recordings were held at $V_{\mathrm{h}}=$ $-60 \mathrm{mV}$. In all the recordings, we used $10 \mathrm{~ms}$ blue-light pulses, indicated by blue bars at the top of the recording traces. Atlas levels are per Paxinos and Franklin (2001).

EPSCs in 43 of 45 recorded HMNs (Fig. $1 C-H$ ). Both effects were blocked by DNQX ( $20 \mu \mathrm{M} ; n=11$; Fig. $1 C, D)$, indicating the release of glutamate and the activation of postsynaptic AMPA receptors. The average photo-evoked EPSC latency was $3.77 \pm 0.17 \mathrm{~ms}(n=43$; Fig. $1 E)$, and the average photoevoked EPSC charge was $1.86 \pm 0.30 \mathrm{pC}(n=43$; Fig. $1 F)$. Responsive neurons exhibited photo-evoked EPSCs following virtually all light pulses (average probability of photo-evoked EPSCs: $98.33 \pm 1.44 \%$ compared with the average probability of spontaneous EPSCs before the light pulses: $17.24 \pm 1.62 \% ; n=$ 43; Fig. 1H).

Photo-evoked EPSCs in HMNs were action potential independent, occurring under conditions of voltage-dependent $\mathrm{Na}$ and $\mathrm{K}$ channel blockade (TTX, $2 \mu \mathrm{M} ; 4-\mathrm{AP}, 1 \mathrm{~mm} ; n=12$ ) supporting direct monosynaptic connectivity between $\mathrm{PH}$ glutamatergic neurons and HMNs (Fig. 1I).
Carbachol inhibits the $\mathrm{PH}^{\text {glut }} \rightarrow$ HMNs input through muscarinic presynaptic receptors

We tested the effects of carbachol on photo-evoked PH ${ }^{\text {glut }}$ EPSCs in HMNs in slices from 16 mice (Fig. 2A,B). Carbachol $(15 \mu \mathrm{M})$ inhibited the photo-evoked EPSCs (charge reduced by $79.42 \pm$ $2.98 \%$ ), and this effect was reversed after a 20 min washout ( $n=8$; RM one-way ANOVA: $F_{(2,14)}=25.58, p<0.0001$; and Tukey's post hoc test: $p=0.0006$ control vs carbachol; $p=0.0039$ washout vs carbachol; and $p>0.05$ control vs wash). When bath applied, scopolamine $(10 \mu \mathrm{M})$, a muscarinic receptor antagonist, abolished the effect of carbachol $(n=5$; RM oneway ANOVA: $F_{(2,8)}=4.47, p>0.05$, comparing photo-evoked EPSC charge in scopolamine vs scopolamine plus carbachol; Fig. 2C,D), indicating that carbachol inhibition of the $\mathrm{PH}^{\text {Glut }} \rightarrow$ HMNs input is mediated by muscarinic receptors.

To examine the presynaptic nature of the carbachol effects, we added GDP- $\beta$-S $(1 \mathrm{~mm})$ to the recording pipette solution to block G-protein-mediated signaling. The effects of carbachol on the $\mathrm{PH}^{\text {Glut }} \rightarrow$ HMNs was preserved while blocking the G-proteins in the recorded HMNs (Fig. $2 E, F ; n=8$ without GDP- $\beta-S ; n=10$ with GDP- $\beta$-S; unpaired $t$ test, $p>0.05$ ). In the presence of GDP- $\beta$-S, carbachol reduced photo-evoked EPSC charges by $77.45 \pm 2.50 \%$ (Fig. $2 F$ ). This result demonstrates that cholinergic inhibition of the $\mathrm{PH}^{\text {Glut }} \rightarrow$ HMNs input is independent of the G-protein signaling in the postsynaptic neurons. We then examined the effect of carbachol on the $\mathrm{PH}^{\text {Glut }} \rightarrow$ HMNs input in the presence of action potential blockade by TTX. We found that the effect of carbachol on the $\mathrm{PH}^{\text {Glut }} \rightarrow$ HMNs input was maintained in the absence of action potentials; in TTX, carbachol reduced the photo-evoked EPSC charge by $59.49 \pm 16.63 \%(n=6$; paired $t$ test, $p=$ 0.028; Fig. 2G,H). Altogether, the results of the recordings with GDP- $\beta$-S in the recording pipette and those in TTX demonstrate that carbachol acts via a presynaptic mechanism.

We recorded HMNs in brain slices from $C h A T^{B A C}-e G F P::$ VGlut2-IRES-Cre mice obtained by crossing ChAT $T^{B A C} C_{-e G F P}$ mice, which express GFP in cholinergic neurons (Tallini et al., 2006) with VGlut2-IRES-Cre mice. We expressed ChR2 in PH glutamatergic neurons by injecting AAV-DIO-ChR2-mCherry into the $\mathrm{PH}$ region, and we recorded from HMNs expressing GFP while photostimulating the $\mathrm{PH}^{\text {Glut }} \rightarrow$ HMNs input (Fig. 2I). Photostimulation of $\mathrm{PH}$ glutamatergic input produced photoevoked EPSCs in all the recorded HMNs labeled by GFP, and carbachol reduced the charge of these photo-evoked EPSC by $70.32 \pm 15.62 \%(n=4$; Fig. $2 J)$.

Altogether, these results demonstrate that cholinergic signaling in the MoXII inhibits the glutamatergic input to HMNs. This 

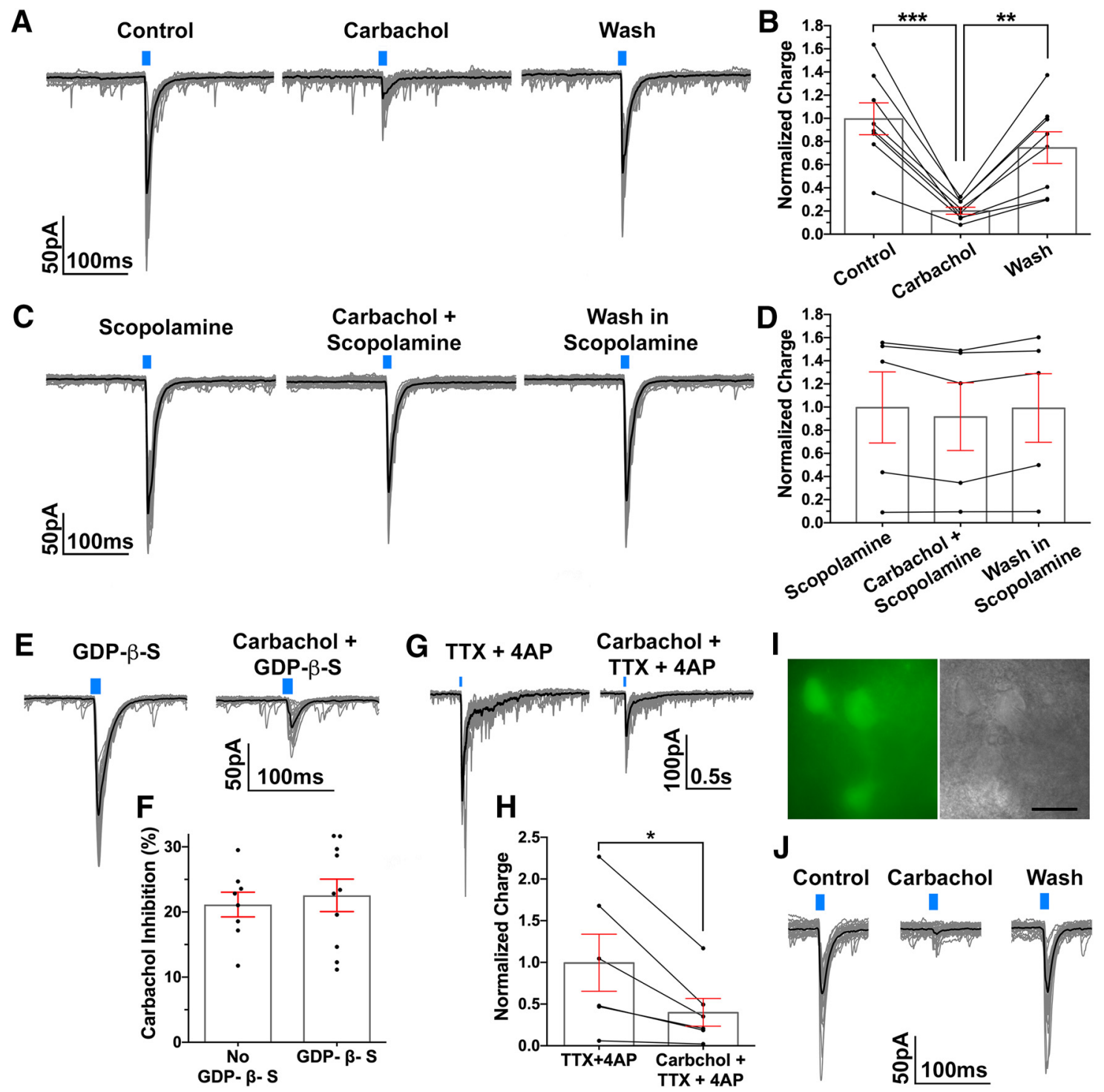

Figure 2. Carbachol inhibits the PH Glut $\rightarrow H M N$ input through muscarinic presynaptic receptors. $A, B$, Carbachol (15 $\mu \mathrm{M})$ reduced the charge of the photo-evoked EPSCs in HMNs. Mean effect of carbachol on the photo-evoked EPSCS ( $\boldsymbol{B}$; mean \pm SEM; $n=8$; RM one-way ANOVA: $F_{(2,14)}=25.58, p<0.0001$; and Tukey's multiple comparison, ${ }^{* *} p<0.01$ and $\left.{ }^{* * *} p<0.001\right)$. C, $\boldsymbol{D}$, The muscarinic receptor antagonist scopolamine $(10 \mu \mathrm{M})$ abolished the effect of carbachol. Mean effect of carbachol on the photo-evoked EPSCs in the presence of scopolamine (D; $n=5$, RM one-way ANOVA: $\left.F_{(2,8)}=4.47, p>0.05\right) . E, F$, Blocking G-protein signaling in the recorded HMNs with GDP- $\beta$-S (1 mm in the recording pipette solution) did not alter the effect of carbachol on photo-evoked EPSCS. Mean carbachol-mediated reduction of photo-evoked EPSC charges with GDP- $\beta$-S $(n=8)$ and without GDP- $\beta$-S $(n=10)$ in the recording pipette $(p>0.05$, unpaired $t$ test). $G, H$, Carbachol inhibited photo-evoked EPSCs recorded in TTX ( $2 \mu \mathrm{M}+4$-AP $1 \mathrm{~mm} ; n=6$; paired $t$ test, $\left.{ }^{*} p=0.028\right) . I$, J, We recorded from HMNs expressing GFP in ChAP ${ }^{B A C}$-eGFP:::VGlut2-IRES-Cre mice while photostimulating the PH Glut $\rightarrow$ HMN input. Carbachol inhibited photo-evoked EPSCs recorded from HMNs labeled by GFP (I, scale bar, $300 \mu \mathrm{m})$. Photo-evoked EPSCs were recorded at $V_{\mathrm{h}}=-60$ $\mathrm{mV}$ (in gray, 30 photo-evoke EPSCs; in black, average photo-evoked EPSCs). In all of the recordings, we used $10 \mathrm{~ms}$ blue-light pulses, indicated by blue bars at the top of the recording traces.

effect is presynaptic and is mediated by the activation of muscarinic receptors on the glutamatergic PH synaptic terminals.

\section{Carbachol inhibits the glutamatergic input from}

\section{parahypoglossal neurons to genioglossus motoneurons}

The PH region at the level of the area postrema contains glutamatergic premotor neurons, which are important for the control of MoXII motor output. Glutamatergic neurons in this region relay the activation of the HMNs in response to upper airway negative pressure (Chamberlin et al., 2007) and/or convey phasic inspiratory drive to the HMNs (Revill et al., 2015; Vann et al., 2018). For the next set of recordings, we restricted the expression of $\mathrm{ChR} 2$ in the $\mathrm{PH}$ region at the level of the area postrema lateral to the MoXII ( $n=7$ mice; Fig. $3 A$ ). Photostimulation produced photo-evoked EPSCs in 24 of 25 recorded HMNs in these mice.
The photo-evoked EPSC had an average latency of $3.85 \pm 0.22$ $\mathrm{ms}$, an average charge of $0.78 \pm 0.12 \mathrm{pC}$, and an average probability of $96.11 \pm 1.84 \%(n=24)$. Carbachol reduced the photoevoked EPSC charge by $84.81 \pm 5.43 \%$ (Fig. $3 B, C ; n=10$; RM one-way ANOVA, $F_{(2,18)}=26.93, p<0.0001$; Tukey's post hoc test, $p<0.0001$ control vs carbachol; $p<0.0001$ washout vs carbachol; $p>0.05$ control vs washout). We made recordings from GMNs retrogradely labeled with fluorescent CTB (Alexa Fluor-488, green; Fig. $4 A$ ) from mice injected with $A A V$-DIOChR2- $m$ Cherry in the $\mathrm{PH}$ region to express ChR2 restricted in neurons lateral to the MoXII (area postrema level; Fig. $4 B, C$ ) as for the recordings in Figure 3. Photostimulation of the PH glutamatergic input produced photo-evoked EPSCs in 14 of 14 recorded GMNs, and carbachol reduced the photo-evoked EPSC charge by $74.53 \pm 5.49 \%$ (Fig. $4 D, E ; n=9$; RM one-way 
A
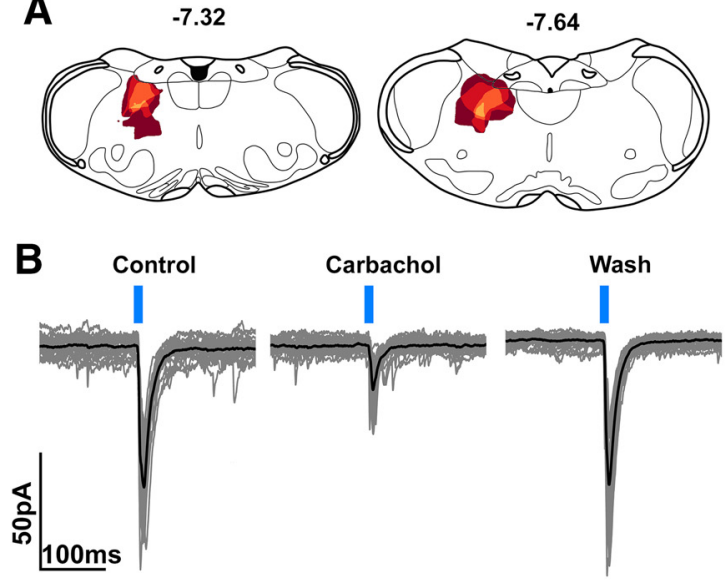

show that direct effects of cholinergic signaling on HMNs are variable, but that muscarinic receptors consistently mediate presynaptic inhibition of important glutamatergic drives to HMNs innervating muscles essential for maintaining airway patency.

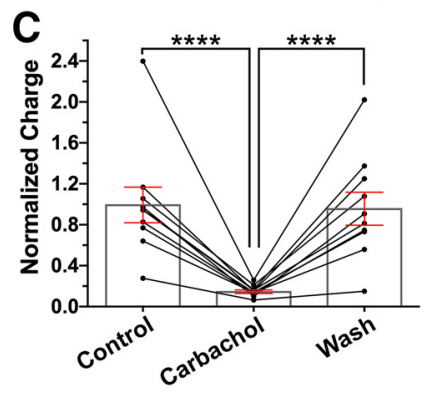

Figure 3. Carbachol inhibits the glutamatergic $\mathrm{PH}^{\text {Glut }} \rightarrow \mathrm{HMN}$ input from the restricted $\mathrm{PH}$ region lateral to the MoXII. $\boldsymbol{A}$, In these recordings, we restricted the expression of ChR2 in the PH region lateral to the MoXII and just at the level of the area postrema. Heatmap of $A A V$-DIO-ChR2-mCherry injection sites of six recorded VGlut2-IRES-Cre mice showing overlapping regions of ChR2-mCherry-expressing neurons. $\boldsymbol{B}, \boldsymbol{C}$, Photostimulation of $\mathrm{PH}^{\text {Glut }}$ input produced photo-evoked EPSCs in HMNs that were inhibited by carbachol (15 $\mu$ m; mean \pm SEM; $n=10$; RM one-way ANOVA: $F_{(2,18)}=26.93, p<0.0001$; and Tukey's multiple comparison, $\left.{ }^{* * * *} p<0.0001\right)$. Photo-evoked EPSCs were recorded at $V_{\mathrm{h}}=-60 \mathrm{mV}$ (in gray, 30 photo-evoke EPSCs; in black, average photo-evoked EPS(s). In all of the recordings, we used $10 \mathrm{~ms}$ blue-light pulses, indicated by blue bars at the top of the recording traces.

ANOVA, $F_{(1,9)}=23.61, p=0.0009$; Tukey's post hoc test, $p=$ 0.0037 control vs carbachol; $p=0.0021$ washout vs carbachol; $p>0.05$ control vs washout). Similar to the previous results, these recordings demonstrate that $\mathrm{PH}$ glutamatergic neurons directly activate GMNs and that this input is inhibited by muscarinic receptors.

\section{Dual postsynaptic muscarinic responses of HMNs to carbachol}

In addition to a presynaptic inhibition of glutamatergic signaling, we found evidence of direct postsynaptic effects on HMNs. Carbachol $(15 \mu \mathrm{M})$ evoked inward or outward currents in HMNs voltage-clamped at $V_{\mathrm{h}}-60 \mathrm{mV}$ and recorded in the presence of TTX (1 mM). Of 29 HMNs, 19 were excited by carbachol (Fig. $5 A$ ), exhibiting an average inward (excitatory) current amplitude of $24.41 \pm 4.60 \mathrm{pA}$ (Fig. $5 E$; paired $t$ test, $p<0.0001$ ); whereas 16 HMNs were inhibited (Fig. $5 B$ ), exhibiting an average outward (inhibitory) current amplitude of $9.82 \pm 1.42 \mathrm{pA}$ (Fig. 5E; paired $t$ test, $p=0.0004$ ). Finally, $30 \%$ of HMNs ( 9 of 29 ) showed a mix of excitatory and inhibitory responses. In the presence of scopolamine $(10 \mu \mathrm{M})$, the carbachol-mediated effects were abolished (Fig. $5 C, E ; n=11$; paired $t$ test, $p>0.05$ ). These results suggest a heterogeneity in muscarinic receptor expression in HMNs in adult mice. Furthermore, adding GDP- $\beta$-S ( $1 \mathrm{~mm})$ in the recording pipette solution to block G-protein signaling in the recorded neurons abolished carbachol-mediated effects (Fig. 5D, E; $n=7$; paired $t$ test, $p>0.05)$. Both carbachol-mediated excitation and inhibition were mediated by muscarinic receptors and were presumably direct effects since they were maintained in the absence of action potential-mediated transmission and depended on G-protein signaling in the postsynaptic neurons.

\section{Discussion}

We provide insight into the cellular mechanisms of REM sleeprelated loss of pharyngeal dilator muscle activity and consequent airway collapse in patients with OSA. Our results confirm and extend previous studies of cholinergic regulation HMNs. We

cated ventral and lateral to the MoXIIhence the "parahypoglossal region" (Tan et al., 2010)—provides dense glutamatergic innervation of the MoXII that originates from VGlut2-expressing neurons (Travers et al., 2005). Accordingly, electrical stimulation of the $\mathrm{PH}$ region evokes glutamatemediated EPSCs in HMNs (Bellingham and Berger, 1996; Thakre and Bellingham, 2017), although with these methods it could not be certain whether local neurons or fibers of passage from other regions were activated.

Here we used in vitro ChR2-assisted circuit mapping to selectively activate the $\mathrm{PH}^{\text {Glut }} \rightarrow \mathrm{HMN}$ and $\mathrm{PH}^{\text {Glut }} \rightarrow$ GMN inputs. We demonstrate monosynaptic functional connectivity between $\mathrm{PH}$ glutamatergic (VGlut ${ }^{+}$) neurons and HMNs and GMNs. We also found that $\sim 95 \%$ of the recorded HMNs and GMNs receive input from $\mathrm{PH}$ VGlut $2{ }^{+}$neurons and that nearly all light pulses evoked EPSCs in the synaptically connected neurons, indicating robust connectivity and high-fidelity activation of the $\mathrm{PH}^{\text {Glut }} \rightarrow \mathrm{H} / \mathrm{GMN}$ inputs. As the expression of ChR2 was anatomically restricted and selective to VGlut2-expressing neurons, we were able to map the origin of the glutamatergic afferent input to the HMNs. Furthermore, our mapping results in cohorts of mice receiving very small AAV injections refine the location of this critical anatomical region to the $\mathrm{PH}$ at the level of the area postrema. Unlike electrical stimulation that activates cell bodies and passing fibers, ChR2-assisted circuit mapping permits the unequivocal demonstration of direct and functional synaptic connectivity between $\mathrm{PH}$ glutamatergic neurons and HMNs and GMNs.

$\mathrm{PH}^{\text {Glut }} \rightarrow \mathrm{H} / \mathrm{GMN}$ inputs are particularly important for respiratory control of the HMNs (Fregosi, 2011; Kubin, 2016). First, the $\mathrm{PH}$ region contains glutamatergic neurons that receive an afferent input from the preBötzinger complex (Tan et al., 2010; Yang and Feldman, 2018), and they convey respiratorysynchronous, phasic inspiratory drive to the HMNs (Revill et al., 2015; Vann et al., 2018). Second, neurons in the $\mathrm{PH}$ region relay the activation of the HMNs in response to upper airway negative pressure (Chamberlin et al., 2007). In humans, this reflex in- 
creases upper airway dilator muscle activity in response to negative pressure in the larynx (Mathew et al., 1982; Horner et al., 1994a), and it ensures upper airway patency during inspiration by opposing the collapse produced by respiratory pump muscle-generated negative pressure (Horner et al., 1991; Zhang and Bruce, 1998; Malhotra et al., 2000a; Ryan et al., 2001). The $\mathrm{PH}^{\text {Glut }} \rightarrow \mathrm{H} / \mathrm{GMN}$ input that we photostimulated may have been part of these circuits.

\section{Cholinergic inhibition of parahypoglossal glutamatergic input to hypoglossal and genioglossus motoneurons}

Earlier data indicate that cholinergic signaling in the MoXII produces a combination of muscarinic- and nicotinic-mediated responses in whole-animal physiology studies (Liu et al., 2005) and in vitro electrophysiological studies (Zaninetti et al., 1999; Bellingham and Funk, 2000; Lape and Nistri, 2000; Chamberlin et al., 2002; Robinson et al., 2002; Ireland et al., 2012; Ghezzi et al., 2017). The cholinergic signal also regulates glutamatergic input to HMNs with muscarinic receptors reducing and nicotinic receptors augmenting glutamatergic input to HMNs (Bellingham and Berger, 1996; Quitadamo et al., 2005). Developmental changes in receptor expression combined with the variety of ages of experimental animals further complicated data interpretation (Funk et al., 1994; Zaninetti et al., 1999; Machaalani et al., 2010; Vivekanandarajah et al., 2015).

Here we eliminated developmental confounds by using mature mice and used optogenetic tools to clarify the synaptic mechanisms of cholinergic regulation in the MoXII. Select activation of the glutamatergic $\mathrm{PH}$ neurons evokes glutamatergic EPSCs in HMNs, including GMNs. Carbachol inhibits the $\mathrm{PH}^{\text {Glut }}$ $\rightarrow \mathrm{HMN}$ and $\mathrm{PH}^{\text {Glut }} \rightarrow \mathrm{GMN}$ inputs. This effect is robust and consistent across all the recorded HMNs and GMNs, and it is mediated by presynaptic muscarinic receptors.

\section{Direct postsynaptic effects of carbachol on HMNs}

Previous in vitro electrophysiology studies have found that cholinergic agonists only excite HMNs, and this effect is mediated by nicotinic receptors (Zaninetti et al., 1999; Chamberlin et al., 2002; Robinson et al., 2002) with a small contribution of muscarinic-mediated excitation (Bellingham and Funk, 2000; Lape and Nistri, 2000; Ireland et al., 2012; Ghezzi et al., 2017). Unlike these studies that were conducted in neonatal animals (mostly postnatal days $0-4$ and up to postnatal day 9), we found in adult mice (6-9 weeks old) that $70 \%$ of HMNs were excited by carbachol, $60 \%$ were inhibited, and $30 \%$ of HMNs had a mix of excitatory and inhibitory responses. Both carbachol-mediated excitation and inhibition were mediated by muscarinic receptors. The lack of nicotinic response in our study is likely due to the
B
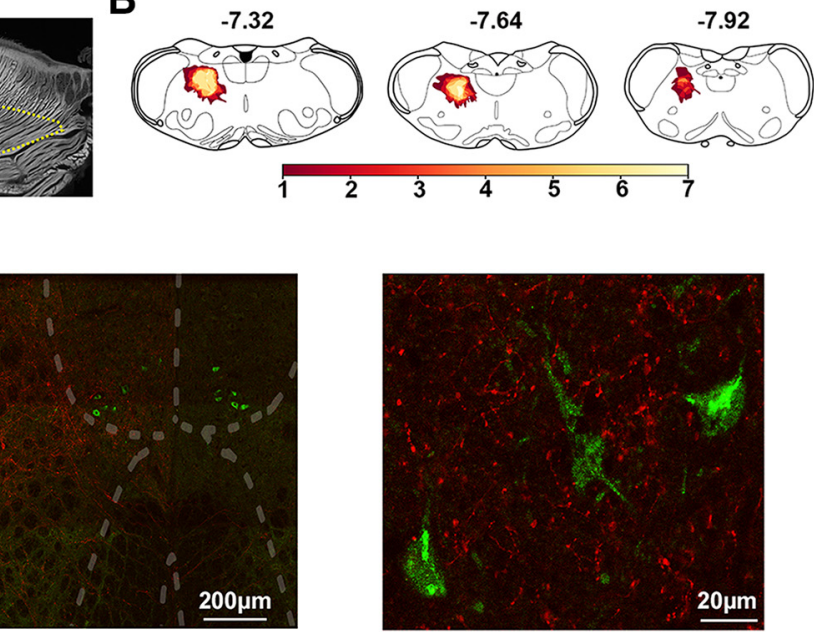

E

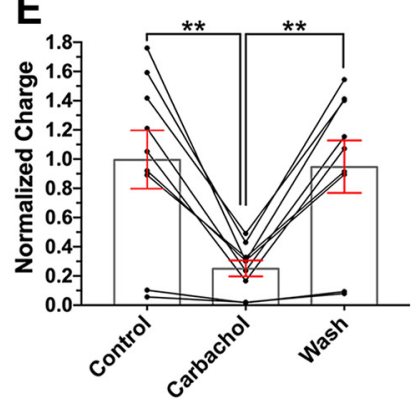

Figure 4. Carbachol inhibits the glutamatergic input from parahypoglossal neurons to genioglossus motoneurons $\left(\mathrm{PH}^{\mathrm{Glut}} \rightarrow\right.$ rex projections expressing ChR2-mCherry. Scale bar, $20 \mu \mathrm{m}$. D, E. Photostimulation produced photo-evoked EPSCs in GMNs and carbachol (15 $\mu$ ) reduced the Tukey's multiple comparison, $\left.{ }^{* *} p<0.01\right)$.

developmental decrease in nicotinic receptor expression. Nicotinic receptors are expressed at high levels in neonates, but their expression decreases significantly in the adult MoXII (Zaninetti et al., 1999; Machaalani et al., 2010; Vivekanandarajah et al., 2015). In adult mice, we found muscarinic-mediated direct inhibition of HMNs. However, this postsynaptic effect was often mixed with a muscarinic-mediated excitation. While the carbacholmediated outward current (inhibitory response) appeared smaller in amplitude than the carbachol-mediated inward current (excitatory response), the relative difference might depend on the membrane potential of the HMNs. Further study will be necessary to establish the physiological conditions under which these mechanisms contribute to tongue function.

\section{Significance of cholinergic control of MoXII motor output}

REM sleep-mediated pharyngeal hypotonia has been attributed to monoaminergic disfacilitation and to direct cholinergic inhibition of HMNs (Grace et al., 2013; Kubin, 2014; Fenik, 2015). Muscarinic antagonists in the MoXII reactivate the genioglossus muscle in REM sleep supporting a cholinergic-mediated depression of genioglossus activity in REM sleep (Grace et al., 2013). There are two main sources of cholinergic afferent input to the 

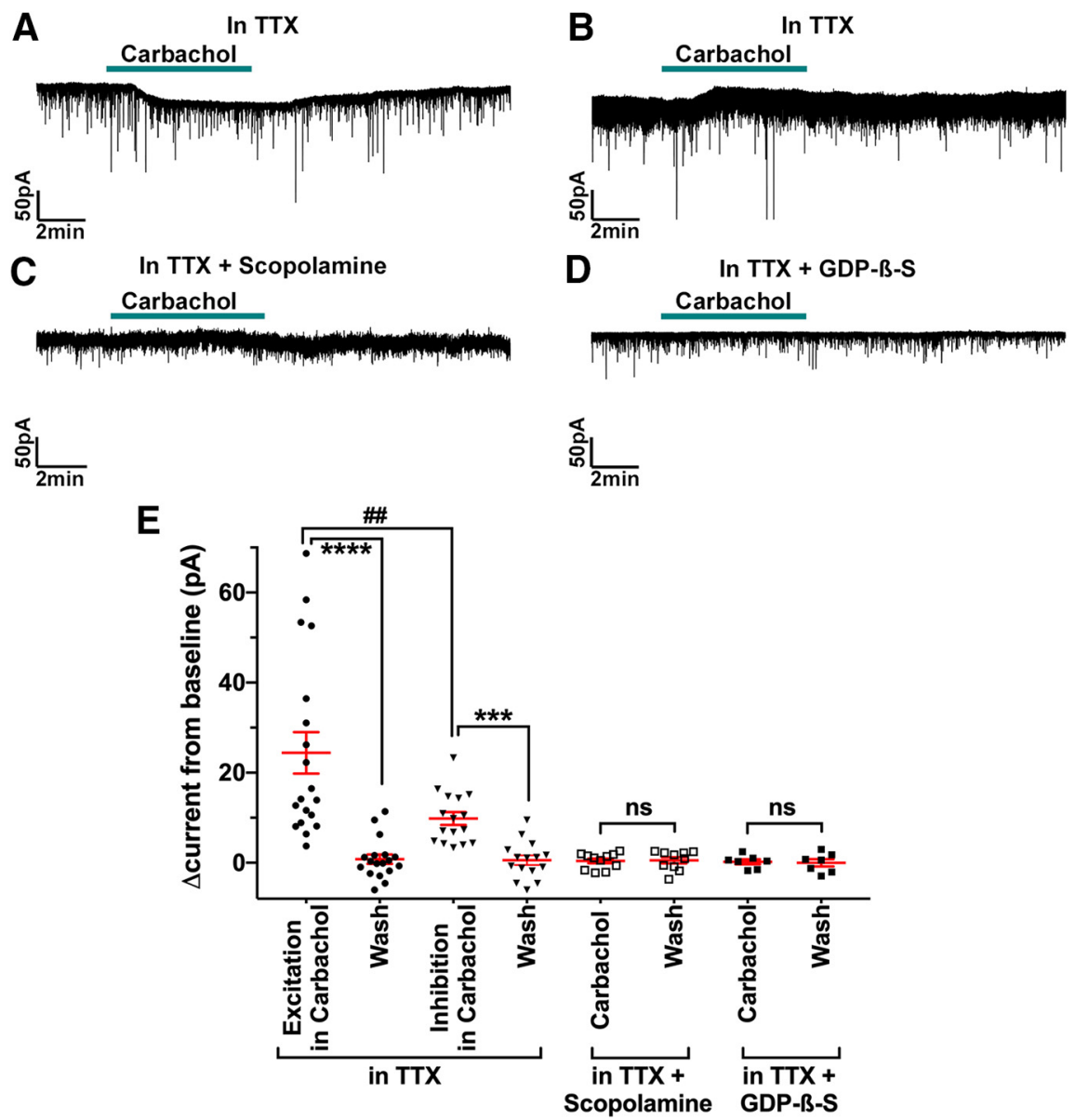

Figure 5. Carbachol postsynaptic effects in HMNs are mediated by muscarinic receptors. $\boldsymbol{A}-\boldsymbol{D}$, Examples of carbachol-mediated responses in HMNs. All recordings were made in voltage-clamp mode at $V_{\mathrm{h}}=-60 \mathrm{mV}$ and in TTX $1 \mu \mathrm{m}$. Green bars represent the duration of carbachol application. Carbachol-mediated inward current ( $\boldsymbol{A}$; excitatory response), carbachol-mediated outward current ( $\boldsymbol{B}$; inhibitory response), and no change in holding current by carbachol in the presence in the bath of scopolamine (10 $\mu \mathrm{M}$; $\boldsymbol{C}$ or when adding GDP- $\beta$-S (1 mM) to the pipette recording solution (D). $\boldsymbol{E}$, Mean amplitude of carbachol-mediated currents (mean \pm SEM; $\Delta$ current from baseline: holding current changes from control to carbachol and to washout) in ACSF (no scopolamine) and in scopolamine. Carbachol-mediated excitation (black circles, $n=19$; paired $t$ test, ${ }^{* * *} p<0.0001$, carbachol vs washout) and carbachol-mediated inhibition (black triangles, $n=16$; paired $t$ test, ${ }^{* * *} p=0.0004$, carbachol vs washout). Carbachol-mediated excitation versus inhibition (unpaired $t$ test, \#\# $p=0.006$ ). Carbachol effects were blocked by scopolamine (white squares; $n=11$; paired $t$ test, $p>0.05$, carbachol in scopolamine vs washout in scopolamine) and by GDP- $\beta$-S (black squares; $n=7$; paired $t$ test, $p>0.05$, carbachol vs washout with GDP- $\beta-S$ ). ns, non-significant.

MoXII: the pedunculopontine tegmental (PPT) and laterodorsal tegmental (LDT) nuclei and cholinergic neurons in the IRt region (Travers et al., 2005; Rukhadze and Kubin, 2007; Volgin et al., 2008). LDT/PPT cholinergic neurons fire in REM sleep, suggesting that they could be the source of REM sleep-related cholinergic inhibition to HMNs (Boucetta et al., 2014), although the density of cholinergic innervation they provide to the MoXII is small (Rukhadze and Kubin, 2007). Conversely, IRt cholinergic neurons provide a denser input to the MoXII (Travers et al., 2005; Volgin et al., 2008), but their physiological role has yet to be demonstrated. Hence, at the moment there is no direct evidence that the cholinergic input to the MoXII is regulated in a statedependent manner. Although the possibility of a cholinergic input to the MoXII primarily active in REM sleep is a valid and eventually testable hypothesis (e.g., using in vivo fiber photometry), it may not be the only explanation for muscarinic antagonists being able to reactivate genioglossus muscle activity during REM sleep. Another possibility is that the cholinergic signal tonically inhibits the HMNs directly and indirectly; for example, through the inhibition of the $\mathrm{PH}^{\text {Glut }} \rightarrow$ HMN input throughout the sleep and wake cycle. While during wakefulness, and in part during NREM sleep, this inhibitory tone is counterbalanced by the monoaminergic activation (Kubin, 2014; Fenik, 2015), it could become unbalanced with the withdrawal of monoaminergic activation during REM sleep. This might explain why the muscarinic antagonists have a smaller effect on genioglossus muscle activity during wakefulness and NREM sleep, but can effectively reactivate the genioglossus muscle in REM sleep (Grace et al., 2013). Although our in vitro experimental approach has inherent limitations, our results extend previous studies by providing a potential mechanism to explain how the blockade of muscarinic transmission during REM sleep disinhibits the HMNs. In future studies, it would be important to demonstrate that optogenetic stimulation of the $\mathrm{PH}^{\text {Glut }} \rightarrow$ HMN input can reactivate the genioglossus muscle in REM sleep and that this effect is enhanced by muscarinic antagonists in the MoXII. These experiments, however, require heavily instrumented animals, which could be a significant challenge in small animals like mice. While this could possibly be achieved in rats, the tools for selective ChR2 expression in selective neuronal population (i.e., the glutamatergic neurons) are unfortunately still lacking.

Numerous studies have established the importance of the tongue muscle in maintaining airway patency and have attributed airway collapse during sleep to state-dependent loss of muscle function. Motor control of the genioglossus is complicated, but the following three main drives are thought to be important: tonic, phasic (time locked to inspiration), and reflexive. All of these three drives are affected by sleep, likely by different mechanisms (Sauerland and Harper, 1976; Orem and Lydic, 1978; Horner, 2017). Cholinergic signaling has been implicated for the REM sleep suppression of genioglossus phasic activity, but it might be less important in controlling tonic activity, as muscarinic antagonists reactivate genioglossus respiratory-related activity in REM sleep, but have a limited effect on tonic genioglossus activity (Grace et al., 2013). Our present results support this idea as the most consistent effect of carbachol was on glutamatergic input rather than directly on HMNs, which would be expected to control tonic activity. Nonetheless, we cannot rule out a contribution of direct inhibition of the HMNs. Moreover, our findings also do not rule out a contribution of monoaminergic disfacilitation to REM sleep-mediated pharyngeal hypotonia. Indeed, recent clinical data showed that the combination of noradrenergic and antimuscarinic agents orally administered before bedtime greatly reduces OSA severity and enhances the genioglossus muscle activity of OSA patients (Taranto-Montemurro et al., 2019), 
suggesting that increased noradrenergic input and decreased muscarinic effects may be synergistic interventions to improve HMN function during sleep.

In summary, we have demonstrated that cholinergic signaling suppresses genioglossus muscle activity through both presynaptic suppression of glutamatergic input from parahypoglossal premotoneurons to HMNs and direct muscarinic-mediated inhibition of HMNs. Our study further highlights the complexity of cholinergic control of HMNs at presynaptic and postsynaptic levels and provides a possible mechanism for REM sleep suppression of genioglossus muscle activity and airway collapse in vulnerable individuals.

\section{References}

Aldes LD (1995) Subcompartmental organization of the ventral (protrusor) compartment in the hypoglossal nucleus of the rat. J Comp Neurol 353:89-108.

Aldes LD, Boone TB (1985) Organization of projections from the principal sensory trigeminal nucleus to the hypoglossal nucleus in the rat: an experimental light and electron microscopic study with axonal tracer techniques. Exp Brain Res 59:16-29.

Bellingham MC, Berger AJ (1996) Presynaptic depression of excitatory synaptic inputs to rat hypoglossal motoneurons by muscarinic $\mathrm{M} 2$ receptors. J Neurophysiol 76:3758-3770.

Bellingham MC, Funk GD (2000) Cholinergic modulation of respiratory brain-stem neurons and its function in sleep-wake state determination. Clin Exp Pharmacol Physiol 27:132-137.

Boucetta S, Cissé Y, Mainville L, Morales M, Jones BE (2014) Discharge profiles across the sleep-waking cycle of identified cholinergic, GABAergic, and glutamatergic neurons in the pontomesencephalic tegmentum of the rat. J Neurosci 34:4708-4727.

Carberry JC, Jordan AS, White DP, Wellman A, Eckert DJ (2016) Upper airway collapsibility (Pcrit) and pharyngeal dilator muscle activity are sleep-stage dependent. Sleep 39:511-521.

Chamberlin NL, Bocchiaro CM, Greene RW, Feldman JL (2002) Nicotinic excitation of rat hypoglossal motoneurons. Neuroscience 115:861-870.

Chamberlin NL, Eikermann M, Fassbender P, White DP, Malhotra A (2007) Genioglossus premotoneurons and the negative pressure reflex in rats. J Physiol 579:515-526.

Dobbins EG, Feldman JL (1995) Differential innervation of protruder and retractor muscles of the tongue in rat. J Comp Neurol 357:376-394.

Fay RA, Norgren R (1997) Identification of rat brainstem multisynaptic connections to the oral motor nuclei using pseudorabies virus. III. lingual muscle motor systems. Brain Res Brain Res Rev 25:291-311.

Fenik VB (2015) Revisiting antagonist effects in hypoglossal nucleus: brainstem circuit for the state-dependent control of hypoglossal motoneurons: a hypothesis. Front Neurol 6:254.

Ferrari LL, Park D, Zhu L, Palmer MR, Broadhurst RY, Arrigoni E (2018) Regulation of lateral hypothalamic orexin activity by local GABAergic neurons. J Neurosci 38:1588-1599.

Fregosi RF (2011) Respiratory related control of hypoglossal motoneurons- knowing what we do not know. Respir Physiol Neurobiol 179:4347.

Fuller DD, Williams JS, Janssen PL, Fregosi RF (1999) Effect of coactivation of tongue protrudor and retractor muscles on tongue movements and pharyngeal airflow mechanics in the rat. J Physiol 519:601613.

Funk GD, Smith JC, Feldman JL (1994) Development of thyrotropinreleasing hormone and norepinephrine potentiation of inspiratoryrelated hypoglossal motoneuron discharge in neonatal and juvenile mice in vitro. J Neurophysiol 72:2538-2541.

Gagnon K, Baril AA, Gagnon JF, Fortin M, Decary A, Lafond C, Desautels A, Montplaisir J, Gosselin N (2014) Cognitive impairment in obstructive sleep apnea. Pathol Biol (Paris) 62:233-240.

Ghezzi F, Corsini S, Nistri A (2017) Electrophysiological characterization of the M-current in rat hypoglossal motoneurons. Neuroscience 340:62-75.

Grace KP, Hughes SW, Horner RL (2013) Identification of the mechanism mediating genioglossus muscle suppression in REM sleep. Am J Respir Crit Care Med 187:311-319.

Horner RL (2009) Emerging principles and neural substrates underlying tonic sleep-state-dependent influences on respiratory motor activity. Philos Trans R Soc Lond B Biol Sci 364:2553-2564.

Horner RL (2017) Respiratory physiology: central neural control of respiratory neurons and motoneurons during sleep. In: Principles and practice of sleep and medicine, Ed 6 (Kryger MH, Roth T, Dement WC, eds), pp 155-166. Philadelphia: Elsevier.

Horner RL, Innes JA, Murphy K, Guz A (1991) Evidence for reflex upper airway dilator muscle activation by sudden negative airway pressure in man. J Physiol 436:15-29.

Horner RL, Innes JA, Morrell MJ, Shea SA, Guz A (1994a) The effect of sleep on reflex genioglossus muscle activation by stimuli of negative airway pressure in humans. J Physiol 476:141-151.

Horner RL, Kozar LF, Kimoff RJ, Phillipson EA (1994b) Effects of sleep on the tonic drive to respiratory muscle and the threshold for rhythm generation in the dog. J Physiol 474:525-537.

Horner RL, Hughes SW, Malhotra A (2014) State-dependent and reflex drives to the upper airway: basic physiology with clinical implications. J Appl Physiol 116:325-336.

Hull C, Adesnik H, Scanziani M (2009) Neocortical disynaptic inhibition requires somatodendritic integration in interneurons. J Neurosci 29:8991-8995

Ireland MF, Funk GD, Bellingham MC (2012) Muscarinic acetylcholine receptors enhance neonatal mouse hypoglossal motoneuron excitability in vitro. J Appl Physiol 113:1024-1039.

Jin XT, Cui N, Zhong W, Jin X, Wu Z, Jiang C (2013) Pre- and postsynaptic modulations of hypoglossal motoneurons by alpha-adrenoceptor activation in wild-type and Mecp2(-/Y) mice. Am J Physiol Cell Physiol 305: C1080-C1090

Krammer EB, Rath T, Lischka MF (1979) Somatotopic organization of the hypoglossal nucleus: a HRP study in the rat. Brain Res 170:533-537.

Krashes MJ, Shah BP, Madara JC, Olson DP, Strochlic DE, Garfield AS, Vong L, Pei H, Watabe-Uchida M, Uchida N, Liberles SD, Lowell BB (2014) An excitatory paraventricular nucleus to AgRP neuron circuit that drives hunger. Nature 507:238-242.

Kubin L (2014) Sleep-wake control of the upper airway by noradrenergic neurons, with and without intermittent hypoxia. Prog Brain Res 209:255274.

Kubin L (2016) Neural control of the upper airway: respiratory and statedependent mechanisms. Compr Physiol 6:1801-1850.

Lape R, Nistri A (2000) Current and voltage clamp studies of the spike medium afterhyperpolarization of hypoglossal motoneurons in a rat brain stem slice preparation. J Neurophysiol 83:2987-2995.

Liu X, Sood S, Liu H, Horner RL (2005) Opposing muscarinic and nicotinic modulation of hypoglossal motor output to genioglossus muscle in rats in vivo. J Physiol 565:965-980.

Machaalani R, Kashi PK, Waters KA (2010) Distribution of nicotinic acetylcholine receptor subunits alpha7 and beta2 in the human brainstem and hippocampal formation. J Chem Neuroanat 40:223-231.

Malhotra A, White DP (2002) Obstructive sleep apnoea. Lancet 360:237245.

Malhotra A, Fogel RB, Edwards JK, Shea SA, White DP (2000a) Local mechanisms drive genioglossus activation in obstructive sleep apnea. Am J Respir Crit Care Med 161:1746-1749.

Malhotra A, Pillar G, Fogel RB, Beauregard J, Edwards JK, Slamowitz DI, Shea SA, White DP (2000b) Genioglossal but not palatal muscle activity relates closely to pharyngeal pressure. Am J Respir Crit Care Med 162:1058 1062.

Mathew OP, Abu-Osba YK, Thach BT (1982) Influence of upper airway pressure changes on genioglossus muscle respiratory activity. J Appl Physiol Respir Environ Exerc Physiol 52:438-444.

Mezzanotte WS, Tangel DJ, White DP (1996) Influence of sleep onset on upper-airway muscle activity in apnea patients versus normal controls. Am J Respir Crit Care Med 153:1880-1887.

Mochizuki T, Arrigoni E, Marcus JN, Clark EL, Yamamoto M, Honer M, Borroni E, Lowell BB, Elmquist JK, Scammell TE (2011) Orexin receptor 2 expression in the posterior hypothalamus rescues sleepiness in narcoleptic mice. Proc Natl Acad Sci U S A 108:4471-4476.

Mu L, Sanders I (2010) Human tongue neuroanatomy: nerve supply and motor endplates. Clin Anat 23:777-791.

Oliven A, Schnall RP, Pillar G, Gavriely N, Odeh M (2001) Sublingual electrical stimulation of the tongue during wakefulness and sleep. Respir Physiol 127:217-226. 
Orem J, Lydic R (1978) Upper airway function during sleep and wakefulness: experimental studies on normal and anesthetized cats. Sleep 1: $49-68$.

Paxinos G, Franklin KBJ (2001) The mouse brain in sterotaxic coordinates. San Diego: Academic.

Petreanu L, Mao T, Sternson SM, Svoboda K (2009) The subcellular organization of neocortical excitatory connections. Nature 457:1142-1145.

Quitadamo C, Fabbretti E, Lamanauskas N, Nistri A (2005) Activation and desensitization of neuronal nicotinic receptors modulate glutamatergic transmission on neonatal rat hypoglossal motoneurons. Eur J Neurosci 22:2723-2734.

Revill AL, Vann NC, Akins VT, Kottick A, Gray PA, Del Negro CA, Funk GD (2015) Dbxl precursor cells are a source of inspiratory XII premotoneurons. Elife 4:e12301.

Robinson DM, Peebles KC, Kwok H, Adams BM, Clarke LL, Woollard GA, Funk GD (2002) Prenatal nicotine exposure increases apnoea and reduces nicotinic potentiation of hypoglossal inspiratory output in mice. J Physiol 538:957-973.

Rukhadze I, Kubin L (2007) Mesopontine cholinergic projections to the hypoglossal motor nucleus. Neurosci Lett 413:121-125.

Rukhadze I, Fenik VB (2018) Neuroanatomical basis of state-dependent activity of upper airway muscles. Front Neurol 9:752.

Ryan S, McNicholas WT, O’Regan RG, Nolan P (2001) Reflex respiratory response to changes in upper airway pressure in the anaesthetized rat. J Physiol 537:251-265.

Sauerland EK, Harper RM (1976) The human tongue during sleep: electromyographic activity of the genioglossus muscle. Exp Neurol 51:160-170.

Shea SA, Edwards JK, White DP (1999) Effect of wake-sleep transitions and rapid eye movement sleep on pharyngeal muscle response to negative pressure in humans. J Physiol 520:897-908.

Stanek E 4th, Cheng S, Takatoh J, Han BX, Wang F (2014) Monosynaptic premotor circuit tracing reveals neural substrates for oro-motor coordination. Elife 3:e02511.

Takahashi T, Kajikawa Y, Tsujimoto T (1998) G-protein-coupled modulation of presynaptic calcium currents and transmitter release by a $\mathrm{GABA}_{\mathrm{B}}$ receptor. J Neurosci 18:3138-3146.

Tallini YN, Shui B, Greene KS, Deng KY, Doran R, Fisher PJ, Zipfel W, Kotlikoff MI (2006) BAC transgenic mice express enhanced green fluorescent protein in central and peripheral cholinergic neurons. Physiol Genomics 27:391-397.

Tan W, Pagliardini S, Yang P, Janczewski WA, Feldman JL (2010) Projections of preBotzinger complex neurons in adult rats. J Comp Neurol 518:1862-1878.

Taranto-Montemurro L, Messineo L, Sands SA, Azarbarzin A, Marques M,
Edwards BA, Eckert DJ, White DP, Wellman A (2019) The combination of atomoxetine and oxybutynin greatly reduces obstructive sleep apnea severity: a randomized, placebo-controlled, double-blind crossover trial. Am J Respir Crit Care Med 199:1267-1276.

Thakre PP, Bellingham MC (2017) Capsaicin enhances glutamatergic synaptic transmission to neonatal rat hypoglossal motor neurons via a TRPV1-independent mechanism. Front Cell Neurosci 11:383.

Travers JB, Yoo JE, Chandran R, Herman K, Travers SP (2005) Neurotransmitter phenotypes of intermediate zone reticular formation projections to the motor trigeminal and hypoglossal nuclei in the rat. J Comp Neurol 488:28-47.

Vann NC, Pham FD, Dorst KE, Del Negro CA (2018) Dbx1 pre-Bötzinger complex interneurons comprise the core inspiratory oscillator for breathing in unanesthetized adult mice. eNeuro 5:ENEURO.0130-18.2018.

Venner A, Anaclet C, Broadhurst RY, Saper CB, Fuller PM (2016) A novel population of wake-promoting GABAergic neurons in the ventral lateral hypothalamus. Curr Biol 26:2137-2143.

Vivekanandarajah A, Waters KA, Machaalani R (2015) Postnatal nicotine effects on the expression of nicotinic acetylcholine receptors in the developing piglet hippocampus and brainstem. Int J Dev Neurosci 47:183-191.

Volgin DV, Rukhadze I, Kubin L (2008) Hypoglossal premotor neurons of the intermediate medullary reticular region express cholinergic markers. J Appl Physiol 105:1576-1584.

Vong L, Ye C, Yang Z, Choi B, Chua S Jr, Lowell BB (2011) Leptin action on GABAergic neurons prevents obesity and reduces inhibitory tone to POMC neurons. Neuron 71:142-154.

White DP (2005) Pathogenesis of obstructive and central sleep apnea. Am J Respir Crit Care Med 172:1363-1370.

Williams RH, Chee MJ, Kroeger D, Ferrari LL, Maratos-Flier E, Scammell TE, Arrigoni E (2014) Optogenetic-mediated release of histamine reveals distal and autoregulatory mechanisms for controlling arousal. J Neurosci 34:6023-6029.

Yang CF, Feldman JL (2018) Efferent projections of excitatory and inhibitory preBotzinger complex neurons. J Comp Neurol 526:1389-1402.

Yokota S, Niu JG, Tsumori T, Oka T, Yasui Y (2011) Glutamatergic kollikerfuse nucleus neurons innervate hypoglossal motoneurons whose axons form the medial (protruder) branch of the hypoglossal nerve in the rat. Brain Res 1404:10-20.

Zaninetti M, Tribollet E, Bertrand D, Raggenbass M (1999) Presence of functional neuronal nicotinic acetylcholine receptors in brainstem motoneurons of the rat. Eur J Neurosci 11:2737-2748.

Zhang X, Bruce EN (1998) Response of breathing pattern to flow and pressure in the upper airway of rats. Respir Physiol 113:191-200. 